\title{
Design of concrete-filled high strength steel tubular $X$-joints subjected to compression
}

\author{
H. T. $\mathrm{Li}^{\mathrm{a} *}$ and B. Young ${ }^{\mathrm{a}}$ \\ ${ }^{a}$ Department of Civil Engineering, The University of Hong Kong, Hong Kong, China \\ *corresponding author, e-mail address: liht@connect.hku.hk
}

\begin{abstract}
Design of concrete-filled high strength steel tubular X-joints subjected to compression is examined. A numerical investigation on concrete-filled high strength steel square and rectangular hollow section $\mathrm{X}$-joints is presented in this paper. The high strength steel tubes had nominal yield stresses of 700 and $900 \mathrm{MPa}$. The infilled concrete had nominal concrete cylinder strengths of 35 and $100 \mathrm{MPa}$. A finite element model was developed and validated against test results. On validation of the finite element model, a parametric study comprised 156 finite element analyses was undertaken using the validated model. The strengths of the concrete-filled high strength steel tubular X-joints obtained from the parametric study together with available test results in the literature were compared with the nominal strengths calculated from the CIDECT Design Guide. It is shown that the CIDECT design predictions exhibited significant scatter and generally conservative for the concrete-filled high strength steel tubular X-joints. However, the CIDECT predictions overestimated the strengths of the concrete-filled high strength steel tubular X-joints with chord sidewall slenderness ratio exceeded 50. Hence, new design rules are proposed for concrete-filled high strength steel square and rectangular hollow section X-joints subjected to compression. It is shown that the proposed design rules are able to provide reasonably good predictions.
\end{abstract}

Keywords: Cold-formed steel; Concrete-filled; Connections; Finite-element analysis; High strength steel; Tubular joints.

\section{Introduction}

Design provisions for concrete-filled tubular joints are available in the Comité International pour Ie Développement et l'Étude de la Construction Tubulaire (CIDECT) Design Guide [1], which is the only existing guideline that provides specific provisions for designing concrete-filled tubular joints. It is noteworthy that for concrete-filled square and rectangular hollow section $\mathrm{X}$-joints under compression, the CIDECT [1] design provisions were developed based on 11 concrete-filled X-joint tests. These 11 tests, as reported in Packer [2], had the measured yield stress on steel tubes of $330 \mathrm{MPa}$. High strength steels are becoming increasingly attractive in a range of structural applications. Although several experimental investigations [36] were carried out on concrete-filled tubular chords under concentrated bearing loads, research into concrete-filled high strength steel tubular joints has been rather limited.
An experimental investigation on concretefilled high strength steel square and rectangular hollow section $\mathrm{X}$-joints subjected to compression was initiated by the authors [7]. The data obtained from the test program [7] are limited and the test specimens covered nominal chord sidewall slenderness ratio up to 40 . In this study, a finite element (FE) model was first developed to replicate the concrete-filled tubular $\mathrm{X}$-joint tests as reported in [7]. After validation of the FE model, a parametric study comprised of $156 \mathrm{FE}$ analyses was performed to generate further numerical data over a wider range of key joint parameters (e.g., chord sidewall slenderness ratio, chord aspect ratio, chord width to thickness ratio and brace to chord width ratio). The investigated chord sidewall slenderness ratio in the parametric study was up to 90 . The appropriateness of the design provisions in the CIDECT [1] to concrete-filled high strength steel tubular X-joint was assessed based on the 
numerical and experimental results. New design rules are proposed for concrete-filled high strength steel tubular X-joints subjected to compression.

\section{Summary of test program}

A series of concrete-filled high strength steel square and rectangular hollow section X-joints subjected to compression have been tested by the authors [7]. In order to avoid brace failure and to reveal the true capacity of the compressionloaded concrete-filled tubular X-joints, steel bearing plates were used to simulate the braces. This method has also been used by Packer [2], based on which the CIDECT design provisions for concrete-filled tubular X-joints under compression were developed.

The concrete-filled high strength steel tubular $\mathrm{X}$-joints had measured chord aspect ratio $\left(h_{0} / b_{0}\right)$ varied between 0.5 and 1.7 , brace to chord width ratio $\left(b_{1} / b_{0}\right)$ varied between 0.33 and 0.83 , chord sidewall slenderness ratio $\left(h_{0} / t_{0}\right)$ ranged from 12.6 to 40.6 , and chord width to thickness ratio $\left(b_{0} / t_{0}\right)$ ranged from 20.3 to 30.9 . The definition of symbols for the X-joints are shown in Figure 1. The investigated high strength steel sections had two nominal steel grades: 700 and $900 \mathrm{MPa}$. The steel grades can be identified from the crosssection labels of the steel tubes, where " $\mathrm{H}$ " and "V" represent nominal steel grades of 700 and $900 \mathrm{MPa}$, respectively. The measured $0.2 \%$ proof stresses from tensile flat coupon tests ranged from 679 to $997 \mathrm{MPa}$. The high strength steel tubular chords were infilled with normal strength concrete (NSC) and high strength concrete (HSC). The NSC (grade C35) and HSC (grade $\mathrm{C} 100)$ had measured concrete cylinder strengths of 36.4 and $95.7 \mathrm{MPa}$, respectively. The experimental investigation is detailed in $\mathrm{Li}$ and Young [7].

\section{Numerical modelling approach}

\subsection{Finite element model}

A finite element (FE) model was developed using FE package ABAQUS [8] to simulate the concrete-filled high strength steel tubular X-joint tests reported by $\mathrm{Li}$ and Young [7]. The FE model was built based on measured geometries. The measured stress-strain curves obtained from tensile coupon tests were used for the coldformed high strength steel tubes. The experimentally obtained stress-strain curves were converted to true stress and true plastic strain curves before incorporating into the model. For the material properties of the concrete infills, the concrete damaged plasticity model that provided by the ABAQUS [8] was used. The employed dilation angle and flow potential eccentricity were $40^{\circ}$ and 0.1 , respectively. The ratio of initial equibiaxial compressive yield stress to initial uniaxial compressive yield stress, and the ratio of the second stress invariant on the tensile meridian to that on the compressive meridian were taken as 1.16 and 0.6 , respectively. To model the compressive behaviour of the confined concrete infills, the uniaxial constitutive confined concrete model used by Yang et al. [9] was adopted in this study.

A 4-node quadrilateral shell element S4R was selected to simulate the high strength steel tube, while an 8-node solid element C3D8R was employed to simulate the infilled concrete. The braces of the X-joint, which were simulated by solid steel bearing plates, were modelled using discrete rigid $3 \mathrm{D}$ elements. The mesh sizes were studied to achieve suitably accurate results within reasonable computational time. The employed mesh sizes ranged from approximately 6 to $12 \mathrm{~mm}$ depending on the size of the tubular sections and finer meshes were used at the corner regions. The structured mesh technique was used in order to achieve proper hexahedral elements.

The interfaces between the high strength steel tubes and their concrete infills were modelled through contact pairs. The surface-to-surface discretization contact approach was applied. The master surfaces were defined in the concrete infill, whereas the slave surfaces were defined in the steel tube. The friction penalty contact with a friction coefficient of 0.6 in the tangential direction was used. The pressure-overclosure relationship in the normal direction used the "hard" contact and allowed separation. The braces of the concrete-filled tubular X-joint were modelled through solid rigid plates. Surface-tosurface contact was also used to define the interfaces between the chords and the solid rigid plates, and the friction penalty contact with a friction coefficient of 0.4 was applied. 

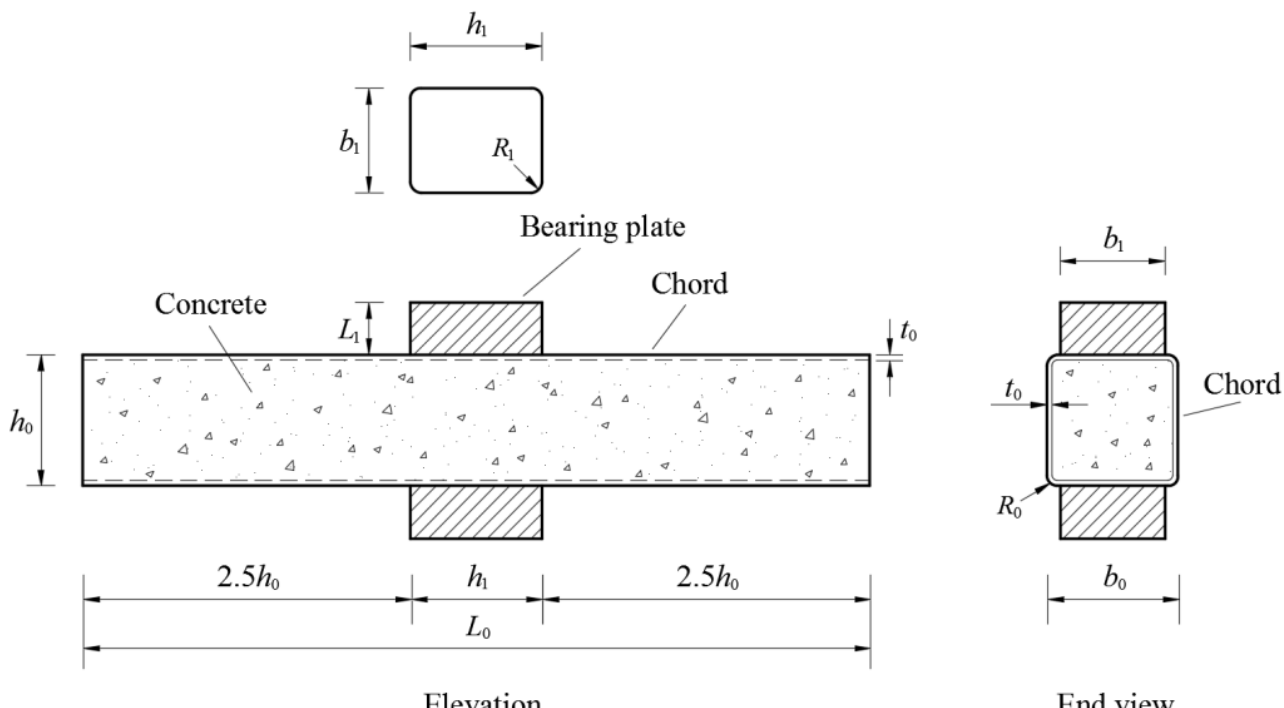

Fig. 1. Definition of symbols for concrete-filled high strength steel tubular X-joints.

The boundary conditions of the tubular Xjoint were modelled in accordance with the test. It is noteworthy that the geometries, boundary conditions and failure modes of the test specimens were symmetric. Hence, only onequarter of the test specimens were modelled and suitable symmetry boundary conditions were applied accordingly. The compressive loads were applied by specifying axial displacements to the reference points of the bearing plates, which was identical to the tests using displacement control.

\subsection{Validation of finite element model}

The FE model was validated against the test results in terms of ultimate strengths, failure modes and load-deformation curves. The ultimate strengths obtained experimentally $\left(N_{\text {Exp }}\right)$ and numerically $\left(N_{\text {FEA }}\right)$ are compared in Table 1 . The mean value of the $N_{\text {Exp }} / N_{\text {FEA }}$ is 0.99 with the corresponding coefficient of variation (COV) of 0.093 . Typical numerical failure modes derived from the FE analyses are compared with the corresponding experimental failure modes in Figures 2 and 3. Typical loaddeformation curves obtained from the FE analyses are also compared with the corresponding experimental curves in Figure 4. Overall, it is shown that the developed FE model is capable of replicating the experimental ultimate strengths, failure modes and loaddeformation histories.

Table 1. Comparison of ultimate strengths obtained from FE analyses with test strengths.

\begin{tabular}{|c|c|c|c|c|c|c|}
\hline Specimen & $b_{1} / b_{0}$ & $b_{0} / t_{0}$ & $h_{0} / t_{0}$ & $N_{\text {Exp }}(\mathbf{k N})$ & $N_{\text {FEA }}(\mathbf{k N})$ & $N_{\text {Exp }} / N_{\text {FEA }}$ \\
\hline $\mathrm{X}-\mathrm{H} 100 \times 100 \times 4-40 \times 40-\mathrm{C} 35$ & 0.39 & 25.6 & 25.5 & 289.5 & 281.3 & 1.03 \\
\hline $\mathrm{X}-\mathrm{H} 100 \times 100 \times 4-40 \times 80-\mathrm{C} 35$ & 0.80 & 25.5 & 25.5 & 398.4 & 440.9 & 0.90 \\
\hline $\mathrm{X}-\mathrm{H} 100 \times 100 \times 4-100 \times 80-\mathrm{C} 35$ & 0.80 & 25.6 & 25.6 & 746.5 & 740.5 & 1.01 \\
\hline X-H120×120×4-40×40-C35 & 0.33 & 30.8 & 30.8 & 305.2 & 294.5 & 1.04 \\
\hline $\mathrm{X}-\mathrm{H} 120 \times 120 \times 4-40 \times 40-\mathrm{C} 100$ & 0.33 & 30.8 & 30.7 & 431.3 & 417.0 & 1.03 \\
\hline $\mathrm{X}-\mathrm{H} 120 \times 120 \times 4-80 \times 100-\mathrm{C} 35$ & 0.83 & 30.9 & 30.8 & 686.8 & 726.6 & 0.95 \\
\hline $\mathrm{X}-\mathrm{H} 120 \times 120 \times 4-80 \times 100-\mathrm{C} 100$ & 0.83 & 30.9 & 30.8 & 1174.1 & 1185.8 & 0.99 \\
\hline X-H50×100×4-40×80-C35 & 0.80 & 25.3 & 12.6 & 910.0 & 1017.5 & 0.89 \\
\hline $\mathrm{X}-\mathrm{H} 50 \times 100 \times 4-40 \times 80-\mathrm{C} 35-\mathrm{R}$ & 0.80 & 25.3 & 12.6 & 892.2 & 1016.4 & 0.88 \\
\hline $\mathrm{X}-\mathrm{H} 50 \times 100 \times 4-40 \times 80-\mathrm{C} 100$ & 0.80 & 25.4 & 12.7 & 981.2 & 1094.6 & 0.90 \\
\hline $\mathrm{X}-\mathrm{H} 50 \times 100 \times 4-100 \times 80-\mathrm{C} 100$ & 0.80 & 25.4 & 12.7 & 4138.2 & 3372.7 & 1.23 \\
\hline $\mathrm{X}-\mathrm{H} 200 \times 120 \times 5-120 \times 80-\mathrm{C} 35$ & 0.67 & 24.2 & 40.6 & 721.9 & 651.4 & 1.11 \\
\hline X-V80×80×4-40×40-C35 & 0.49 & 20.4 & 20.3 & 338.5 & 355.4 & 0.95 \\
\hline $\mathrm{X}-\mathrm{V} 80 \times 80 \times 4-40 \times 40-\mathrm{C} 100$ & 0.49 & 20.3 & 20.3 & 464.0 & 453.5 & 1.02 \\
\hline \multirow[t]{2}{*}{$\mathrm{X}-\mathrm{V} 80 \times 80 \times 4-80 \times 40-\mathrm{C} 35$} & 0.50 & 20.3 & 20.3 & 569.2 & 588.7 & 0.97 \\
\hline & & & & & $\begin{array}{l}\text { Mean } \\
\text { COV }\end{array}$ & $\begin{array}{c}0.99 \\
0.093\end{array}$ \\
\hline
\end{tabular}




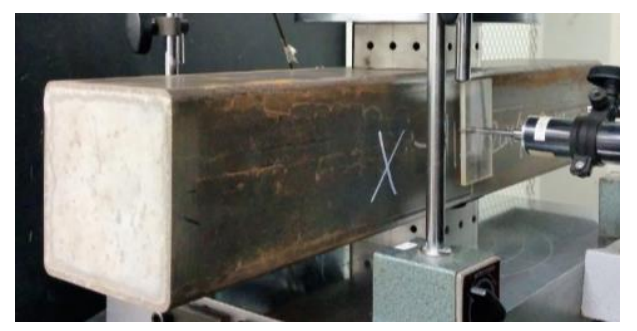

(a) Experimental failure mode

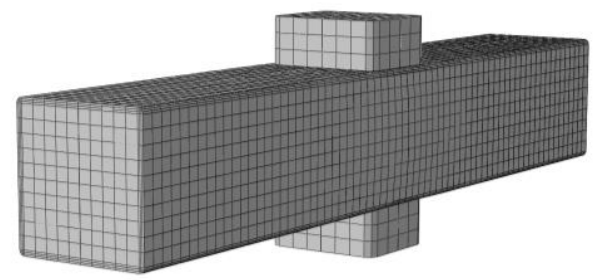

(b) Numerical failure mode

Fig. 2. Experimental and numerical failure modes of specimen X-H120×120×4-80×100-C100.

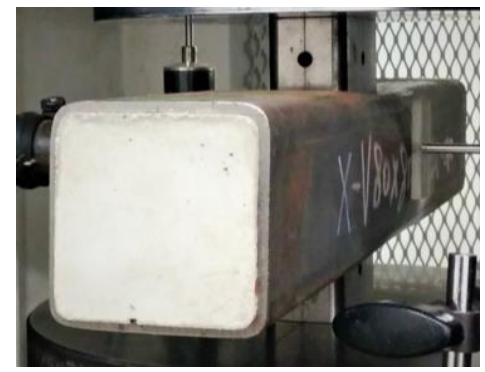

(a) Experimental failure mode

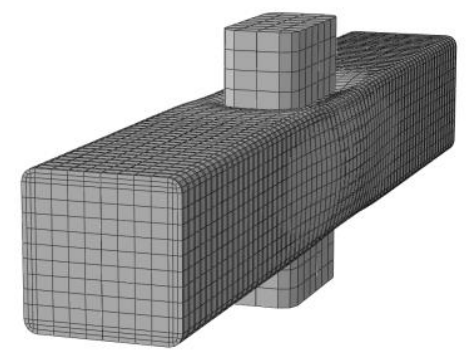

(b) Numerical failure mode

Fig. 3. Experimental and numerical failure modes of specimen $\mathrm{X}-\mathrm{V} 80 \times 80 \times 4-80 \times 40-\mathrm{C} 35$.

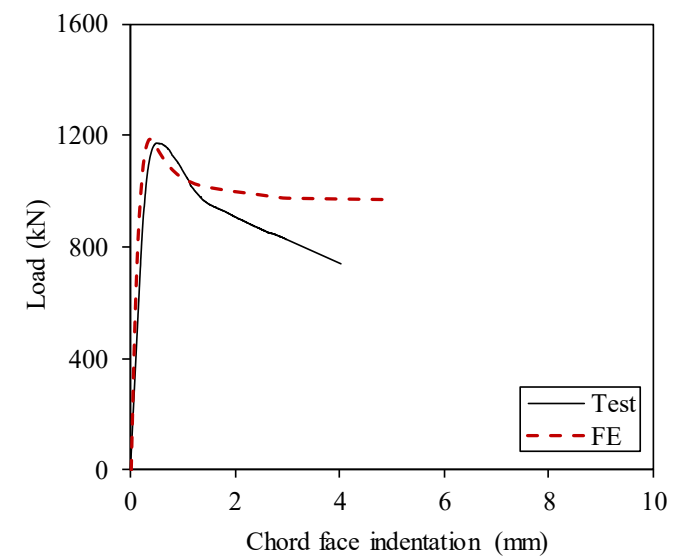

(a) Load-chord face indentation curves

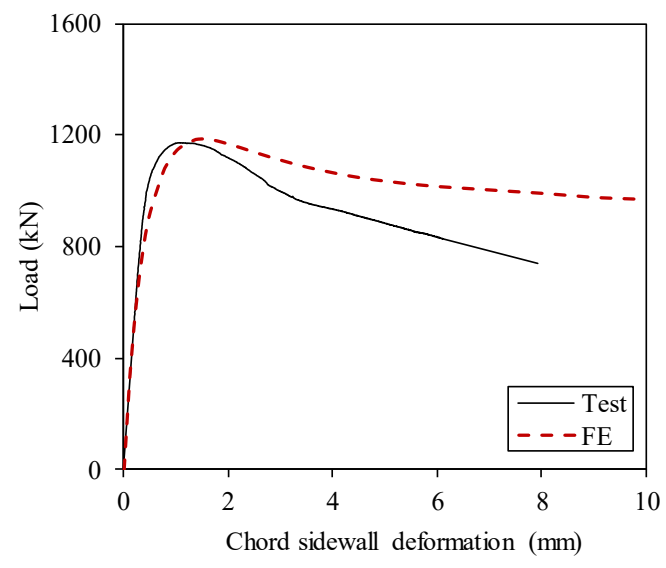

(b) Load-chord sidewall deformation curves Fig. 4. Comparison of test and FE load-deformation

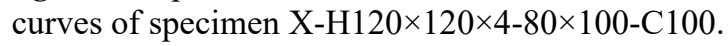

\subsection{Parametric study}

The test program reported by the authors [7] covered concrete-filled high strength steel tubular X-joints with the $b_{1} / b_{0}$ ratio from 0.33 to $0.83, b_{0} / t_{0}$ ratio from 20.3 to $30.9, h_{0} / t_{0}$ ratio from 12.6 to 40.6 , and $h_{0} / b_{0}$ ratio from 0.5 to 1.7 . In order to expand the database, a parametric study was undertaken using the validated model to generate further numerical data over a wider range of the key joint parameters.

In the parametric study, the chord members covered 26 different square and rectangular hollow sections. These tubular sections were selected from the range of practical cross-section sizes for structural applications. The selected sections had overall depths ranged from 140 to $400 \mathrm{~mm}$, overall widths ranged from 100 to 400 $\mathrm{mm}$, and steel wall thicknesses ranged from 2 to $10 \mathrm{~mm}$. The steel grades of the square and rectangular hollow sections were 700 and 900 $\mathrm{MPa}$, being referred as " $\mathrm{H}$ " and "V" series, respectively. The measured material properties obtained from the coupon tests of sections $\mathrm{H} 100 \times 100 \times 4$ and $\mathrm{V} 80 \times 80 \times 4$ were used for the " $\mathrm{H}$ " and "V" series, respectively. The lengths of the chords were designed such that the clear distance from the end of the chord member to the edge of the steel bearing plate was $2.5 h_{0}$, as illustrated in Figure 1. For each concrete-filled high strength steel tubular chord member, 3 different sizes of bearing plates were designed to simulate different brace members. Both NSC (C35) and HSC (C100) infills were studied and the tubular chord members were infilled with grade $\mathrm{C} 35$ or $\mathrm{C} 100$ concrete along their full chord lengths. 
In total, 156 parametric results were generated. The concrete-filled high strength steel tubular X-joints in the parametric study had $b_{1} / b_{0}$ ratio ranged from 0.25 to $0.93, b_{0} / t_{0}$ ratio ranged from 15 to $90, h_{0} / t_{0}$ ratio ranged from 15 to 90 and $h_{0} / b_{0}$ ratio ranged from 0.5 to 2.5 . It should be noted that the investigated $h_{0} / b_{0}$ ratio goes beyond the CIDECT [1] limit of 1.4. The ultimate strengths $\left(N_{\mathrm{FEA}}\right)$ of the specimens in the parametric study were obtained. Note that the ultimate strengths were taken as the peak load or the load of $3 \% b_{0}$ deformation limit as specified in the CIDECT, whichever occurs earlier in the load-chord face indentation curves. The same approach has been employed by the authors [7] to determine the ultimate strengths of concretefilled high strength steel tubular X-joints in the test program.

\section{CIDECT design provisions comparison with joint strengths}

and

Design provisions for concrete-filled square and rectangular hollow section X-joints are available in the current CIDECT Design Guide No.3 [1]. The CIDECT [1] is also the only existing design guideline that has specific provisions for concrete-filled tubular joints. For concrete-filled tubular X-joints with braces in compression, the CIDECT design provisions were developed based on the research carried out by Packer [2], where a total of 11 concrete-filled $\mathrm{X}$-joint specimens were tested. The design provisions were derived from concrete bearing models and the contribution of the steel tube was ignored to form a conservative lower bound method. The equation recommended by the CIDECT for compression-loaded concrete-filled square and rectangular hollow section $\mathrm{X}$-joints with braces perpendicular to the chords can be illustrated as follows,

$$
N_{\text {CIDECT }}=A_{1} f_{\mathrm{c}}^{\prime}\left(A_{2} / A_{1}\right)^{0.5}
$$

where, $N_{\text {CIDECT }}$ is the nominal strength; $f_{\mathrm{c}}^{\prime}$ is the compressive cylinder strength of the infilled concrete; $A_{1}=b_{1} h_{1}$ is the bearing area over which the transverse bearing load applied; $A_{2}$ is the dispersed bearing area. It is specified in the CIDECT [1] that the $A_{2}$ shall be determined by dispersion of the bearing load at a slope of 2:1 longitudinally along the chord and the dispersed bearing area $A_{2}$ equals to $b_{1}\left(h_{1}+2 h_{0}\right)$. It is noteworthy that the CIDECT [1] restricts the
$\left(A_{2} / A_{1}\right)^{0.5}$ values with an upper limit of 3.3 for concrete-filled X-joints.

The feasibility of applying the CIDECT design provisions to concrete-filled high strength steel tubular $\mathrm{X}$-joints is evaluated herein by comparing the test and FE strengths $\left(N_{\mathrm{u}}\right)$ with the nominal strengths $\left(N_{\text {CIDECT }}\right)$ predicted by the CIDECT [1]. A total of 171 available data was used for the comparison, including 15 test data [7] and 156 numerical data obtained in this study. The comparison results are tabulated in Table 2 where the mean value of the $N_{\mathrm{u}} / N_{\text {CIDECT }}$ ratio is 1.24 with a very large COV of 0.852 . The comparison results are also graphically shown in Figure 5, where the $N_{\mathrm{u}} / N_{\text {CIDECT }}$ values exhibit significant scatter and the $N_{\mathrm{u}} / N_{\text {CIDECT }}$ ratio generally decreases as the $h_{0} / t_{0}$ ratio increases. For relatively stocky steel sections $\left(h_{0} / t_{0} \leq 20\right)$, the CIDECT predictions are always overly conservative. One of the possible reasons for this could be due to the contribution of the steel tube is ignored in the CIDECT design formula. In addition, the $N_{\mathrm{u}} / N_{\text {CIDECT }}$ values for the specimens with NSC (normal strength concrete) are always greater than their HSC (high strength concrete) counterparts. This may be explained by the fact that the CIDECT design provisions consider the same degree of confinement for different concrete infills.

Table 2. Comparison of test and FE results with design predictions.

\begin{tabular}{ccc}
\hline Parameters & $\boldsymbol{N}_{\mathbf{u}} / \boldsymbol{N}_{\mathbf{C I D E C T}}$ & $\boldsymbol{N}_{\mathbf{u}} / \boldsymbol{N}_{\mathbf{p}}$ \\
\hline No. of specimens & 171 & 171 \\
Mean & 1.24 & 1.06 \\
COV & 0.852 & 0.235 \\
\hline
\end{tabular}

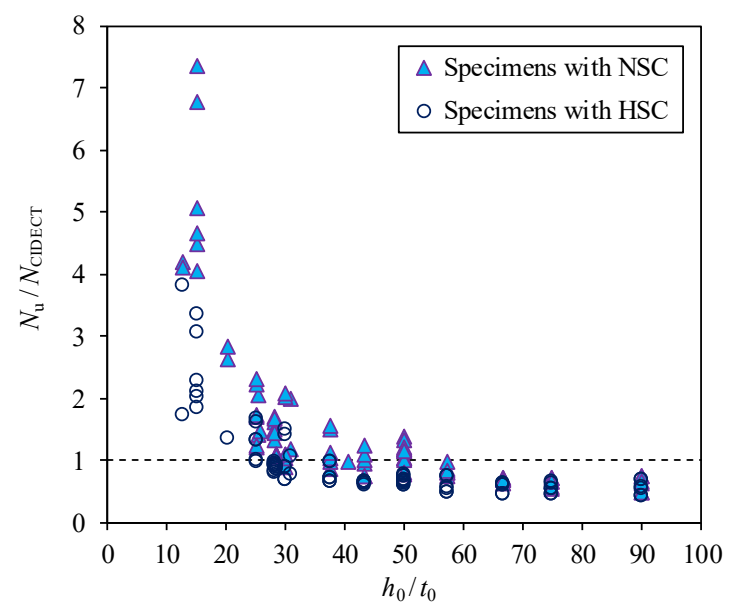

Fig. 5. Comparison of test and FE results with CIDECT predictions. 
Overall, the design provisions in the CIDECT [1] provide conservative strength predictions for the high strength steel tubular $\mathrm{X}$-joints filled with NSC for $h_{0} / t_{0}$ ratio up to 40 , as shown in Figure 5. For the X-joints filled with HSC, the CIDECT [1] design provisions give generally conservative predictions for $h_{0} / t_{0}$ ratio up to 25 , beyond which the CIDECT design provisions generally yield over-optimistic predictions. It should be noted that the design provisions recommended by the CIDECT [1] were developed on the basis of concrete-filled X-joint tests with chord sidewall slenderness ratio varied between 26.9 and 37.4. Besides, the infilled concrete of these tests had cylinder strengths of 43.3 $\mathrm{MPa}$ and the yield stress of the steel tubes was $330 \mathrm{MPa}$. The CIDECT [1] design provisions consider the concrete confinement effect through the $\left(A_{2} / A_{1}\right)^{0.5}$ value only, which is irrelevant to the materials, steel wall thickness and chord sidewall slenderness ratio. It is found that the $A_{2}$ determined by dispersing the bearing area longitudinally at a slope of $2: 1$ to the centre depth of the chord could lead to unconservative predictions for concrete-filled tubular X-joints with relatively slender steel sections. In this study, the CIDECT [1] design provisions overestimate the strengths of the concrete-filled high strength steel tubular X-joints with chord sidewall slenderness ratio above 50 .

\section{Proposed design rules and comparison with joint strengths}

In this study, new design rules are proposed for concrete-filled high strength steel tubular Xjoints subjected to compression. The proposed design rules consider the contribution of the high strength steel tube as well as the confinement effect of the concrete. The proposed formula is expressed in Eq. (2), where $N_{\mathrm{p}}$ is the proposed nominal strength, $N_{\mathrm{s}}$ is the joint strength contributed by the high strength steel tubular section, $N_{\mathrm{c}}$ is the joint strength contributed by the concrete; $A_{\mathrm{s}}$ and $f_{\mathrm{y} 0}$ are the cross-sectional area and yield stress of the high strength steel section, respectively; $A_{\mathrm{c}}$ and $f_{\mathrm{c}}^{\prime}$ are the cross-sectional area and the cylinder strength of the concrete infill, respectively.

$$
N_{\mathrm{P}}=N_{\mathrm{s}}+N_{\mathrm{c}}\left[0.9+1.3 \frac{t_{0}}{h_{0}}\left(\frac{A_{\mathrm{s}} f_{\mathrm{y} 0}}{A_{\mathrm{c}} f_{\mathrm{c}}^{\prime}}\right)^{2}\right]
$$

In Eq. (2), the calculation of the $N_{\mathrm{s}}$ employed the design formulae in Table 7.11 of the European Code [10]. For X-joints with braces perpendicular to the chords, the $N_{\mathrm{s}}$ is to be obtained as follows,

For $\beta=1.0\left(b_{1} / b_{0}=1.0\right)$ :

$N_{\mathrm{s}}=k_{n} f_{b} t_{0}\left(2 h_{1}+10 t_{0}\right)$

For $\beta \leq 0.85\left(b_{1} / b_{0} \leq 0.85\right)$ :

$$
N_{\mathrm{s}}=\frac{k_{n} f_{\mathrm{y} 0} t_{0}^{2}}{(1-\beta)}\left(\frac{2 h_{1}}{b_{0}}+4 \sqrt{1-\beta}\right)
$$

For $0.85<\beta<1.0\left(0.85<b_{1} / b_{0}<1.0\right)$, the $N_{\mathrm{s}}$ can be obtained by using linear interpolation between the value at $\beta=0.85$ and the governing value at $\beta=1.0$. In Eqs. (3) and (4), $k_{n}$ is the chord stress function and the $f_{b}$ is the chord sidewall flexural buckling stress as detailed in Table 7.11 of the European Code [10]. In this study, the value of $k_{n}$ was taken as 1.0.

The calculation of the $N_{\mathrm{c}}$ is shown in Eq. (5), which was developed in the same way as the current CIDECT [1] design provisions.

$N_{\mathrm{c}}=A_{1} f_{\mathrm{c}}^{\prime}\left(A_{2} / A_{1}\right)^{0.5}$

where, $f_{\mathrm{c}}^{\prime}$ is the compressive concrete cylinder strength; $A_{1}=b_{1} h_{1}$ is the bearing area over which the transverse load is applied; $A_{2}$ is the dispersed bearing area. It should be noted that instead of dispersing the bearing load longitudinally only, the $A_{2}$ was determined by dispersion of the bearing load in both the longitudinal and lateral directions along the chord member in the concrete area. The dispersion slope of 1:1 in both the longitudinal and lateral directions that recommended by Feng and Young [11] was adopted in calculating the $A_{2}$.

The comparison results of the $N_{\mathrm{u}}$ with the $N_{\mathrm{p}}$ are shown in Table 2. The mean value of the $N_{\mathrm{u}}$ $/ N_{\mathrm{p}}$ ratio is 1.06 with the corresponding COV of 0.235 . It can be observed that the proposed $N_{\mathrm{p}}$ are able to provide reasonably good predictions for the concrete-filled high strength steel tubular $\mathrm{X}$-joints, as shown in Figure 6. The validity ranges for the proposed design rules are $0.25 \leq$ $b_{1} / b_{0} \leq 0.93,12.6 \leq h_{0} / t_{0} \leq 90.0,15.0 \leq b_{0} / t_{0} \leq$ 90.0 and $0.5 \leq h_{0} / b_{0} \leq 2.5$, and most of these ranges are beyond the current limit of the CIDECT [1] design provisions. 


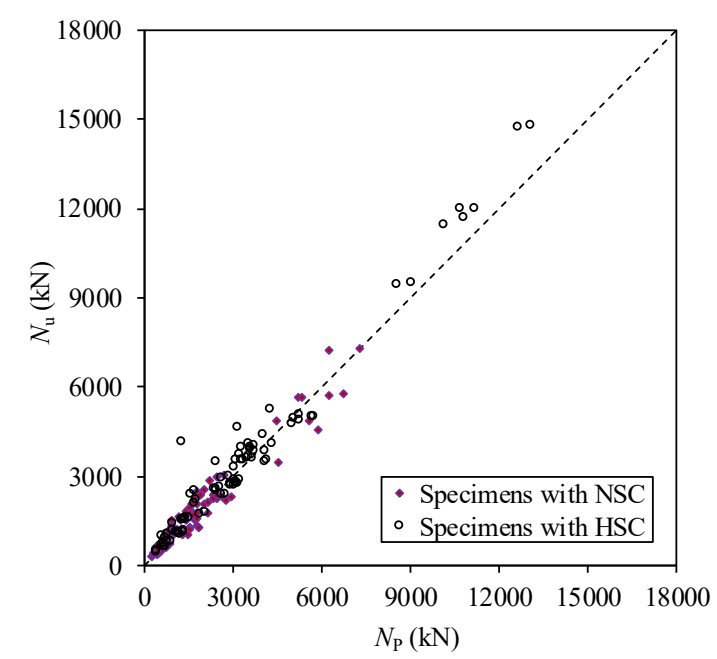

Fig. 6. Comparison of test and FE results with proposed design rules.

In addition, the test strengths $\left(N_{1 \mathrm{U}}\right)$ of the 11 concrete-filled X-joint specimens reported by Packer [2] were also compared with the $N_{\mathrm{p}}$ calculated from Eq. (2). Note that the CIDECT [1] design provisions were developed based on these concrete-filled X-joint tests. The comparison of the $N_{1 \mathrm{U}}$ and $N_{\mathrm{p}}$ are illustrated in Figure 7. It is shown that the proposed design rules are capable of providing conservative predictions for all the compression-loaded concrete-filled X-joint tests reported by Packer [2].

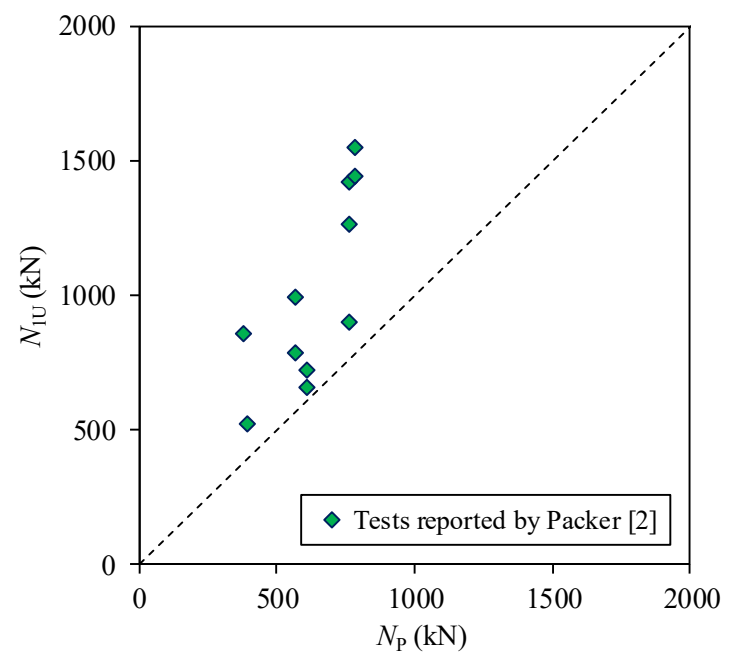

Fig. 7. Comparison of test strengths reported by Packer [2] with proposed nominal strengths.

\section{Conclusions}

In this paper, a numerical investigation was performed on concrete-filled high strength steel square and rectangular hollow section $\mathrm{X}$-joints subjected to compression. The nominal yield stresses of the steel tubes and the nominal cylinder strengths of the concrete infills were up to 900 and $100 \mathrm{MPa}$, respectively. A finite element (FE) model was developed and validated against the test results. On validation, a parametric study comprised $156 \mathrm{FE}$ analyses was performed in order to generate further numerical data over a wide range of key parameters.

The ultimate strengths generated from the parametric study together with those from available tests were compared with the nominal strengths calculated from the CIDECT [1] design provisions. It has been shown that the CIDECT predictions exhibited significant scatter and were overly conservative for the Xjoints with stocky tubular sections. In contrast, the CIDECT [1] overestimated the strengths of the concrete-filled high strength steel tubular Xjoints when the chord sidewall slenderness values exceeded 50. Hence, new design rules have been proposed in this study for concretefilled high strength steel tubular $\mathrm{X}$-joints subjected to compression. It has been shown that the proposed design rules are able to provide reasonably good predictions.

\section{Acknowledgement}

The research work described in this paper was supported by a grant from the Research Grants Council of the Hong Kong Special Administrative Region, China (Project No. 17209614).

\section{References}

[1] CIDECT. Design guide for rectangular hollow section (RHS) joints under predominantly static loading. Second Edition, Comité International pour Ie Développement et l'Étude de la Construction Tubulaire, LSS Verlag, Dortmund, Germany; 2009.

[2] Packer JA. Concrete-filled HSS connections. Journal of Structural Engineering 1995;121(3): 458-467.

[3] Zhao X-L. Partially stiffened RHS sections under transverse bearing force. Thin-Walled Structures 1999;35:193-204.

[4] Feng R, Young B. Behaviour of concrete-filled stainless steel tubular $\mathrm{X}$-joints subjected to compression. Thin-Walled Structures 2009; 47(4):365-374.

[5] Hou C, Han L-H, Zhao X-L. Concrete-filled circular steel tubes subjected to local bearing 
force: Experiments. Journal of Constructional Steel Research 2013;83:90-104.

[6] Yang Y-F, Hou C, Wen Z, and Han L-H. Experimental behaviour of square CFST under local bearing forces. Thin-Walled Structures 2014;74:166-183.

[7] Li H-T, Young B. Tests of concrete-filled high strength steel tubular X-joints. Proceedings of the 16th International Symposium on Tubular Structures. Melbourne, Australia; 2017.

[8] ABAQUS. Abaqus/Standard user's manual volumes I-III and Abaqus CAE manual. Version 6.12. Hibbitt, Karlsson \& Sorensen, Inc., Pawtucket, USA; 2012.
[9] Yang Y-F, Wen Z, Dai X-H. Finite element analysis and simple design calculation method for rectangular CFSTs under local bearing forces. Thin-Walled Structures 2016;106:316329.

[10]CEN. European Committee for Standardization. EN 1993-1-8, Eurocode 3: Design of steel structures - Part 1-8: Design of joints. Brussels, Belgium; 2005.

[11]Feng R, Young B. Design of concrete-filled stainless steel tubular connections. Advances in Structural Engineering 2010;13(3):471-492. 